\title{
3rd International Meeting on Molecular Epidemiology and Evolutionary Genetics of Infectious Diseases
}

\author{
7-10 June 1998 - Rio de Janeiro, RJ
}

\section{FOREWORD}

The Third International Workshop on Molecular Epidemiology and Evolutionary Genetics of Infectious Diseases was held at the Hotel Glória in Rio de Janeiro, Brazil, from June 7 to 10, 1998. The title of this third meeting was broadened to cover infectious diseases so as to include both vector and host aspects as well as pathogenic micro-organisms.

The 11 plenary lectures and 14 round-tables presented during this workshop covered a wide variety of diseases from a number of different perspectives. The abstracts received from over 20 countries and six continents attested to the popularity and widespread appeal of these meetings. Brazil was an appropriate setting for this meeting as most of the infectious diseases discussed during this workshop are either emerging, re-emerging or endemic in this country. These international meetings started from an idea shared between Michel Tibayrenc and Altaf Lal. The first meeting was held in June 1996 in Atlanta GA, USA and the second in Montpellier in May 1997. These two meetings were co-sponsored by ORSTOM (the National French Agency for scientific research in developing countries), CNRS (the National French Agency for basic research) and the Centers for Disease Control and Prevention (CDC). For this third meeting the Oswaldo Cruz Institute of the Oswaldo Cruz Foundation joined the original sponsors. The Oswaldo Cruz Institute was founded in Rio de Janeiro in the beginning of this century and has a distinguished record of achievements in the field of research and control of infectious diseases. Since these meetings were founded the importance of the molecular epidemiological and evolutionary genetic approach to infectious diseases has been increasingly demonstrated in the identification and control of many outbreaks. Several practical examples of the use of this approach were given in the talks during the meeting. The full program and abstracts of all the presentations (plenary lectures, roundtables and posters) are available at the web-site for the event http://www.dbbm.fiocruz.br/www-mem/ meeting. In addition the speakers of the oral presentations were invited to submit manuscripts to be considered for publication in the Memórias. In order for the manuscripts to be published shortly after the meeting a deadline was imposed for the submission of the manuscripts. Due to the short time available many speakers were unable to make submissions, however those who sent manuscripts and which were approved for publication are included in this issue of the journal.

We would like to thank the following organizations for their financial support of this meeting: $\mathrm{CNPq}$ (The Brazilian National Research Council), FAPERJ (The State of Rio de Janeiro Research Council), CAPES (The Brazilian Agency for post-graduate studies), FNS (The Brazilian National Health Foundation), INTERACTIVA Biotechnologie Gmbh and Sigma Chemical Co. (Brazil). We would also like to acknowledge the support of the Brazilian societies of Mycology, Virology and Microbiology.

From the many comments received both during and after the workshop it can be concluded that the meeting was very successful, both in terms of the high quality of the presentations and in the opportunities provided by the intervals and social program for contacts and interactions among the participants. The National press also took great interest in the workshop and articles appeared in newspapers and magazines, before, during and after the meeting as well as material, on television news and radio.

The success of this meeting bodes well for the next workshop which is planned for Dakar, Senegal in June 1999. Further information about this meeting can be obtained from Dr Michel Tibayrenc (fax: $+33-$ 4-67416299) or from the organizers below.

The organizers

Hooman Momen

(hmomen@gene.dbbm.fiocruz.br)

Altaf A Lal

(aall@cdc.gov)

Michel Tibayrenc

(Michel.Tibayrenc@cepm.mpl.orstom.fr) 